\title{
CARGOS Y OFICIOS MUNICIPALES EN LAS CIUDADES DE LEÓN, ZAMORA Y SALAMANCA DURANTE EL REINADO DE CARLOS III
}

\author{
Alfredo GÓMEZ MARTíNEZ \\ Universidad de León
}

\begin{abstract}
RESUMEN: Durante la Edad Moderna en las ciudades de León, Zamora y Salamanca el gobierno de los respectivos municipios lo detenta un corregidor, un alcalde mayor, un número variable de regidores y un procurador síndico general, conocido en Salamanca como sexmero del común. Con la subida al trono de Carlos III y como consecuencia de su política absolutista, centralista y reformista surgen dos nuevas figuras dentro del organigrama municipal: los personeros y los diputados del común. El objetivo de este trabajo es el de analizar el origen, funcionamiento y forma de elección de estos seis cargos y de los oficiales municipales que trabajan junto a ellos.
\end{abstract}

PALABRAS CLAVE: León, Zamora, Salamanca, municipios, Carlos III, cargos y oficiales municipales.

ABSTRACT: During the Modern Age in the cities of León, Zamora and Salamanca the government of the respective municipalities are held by a "corregidor", an "alcalde mayor", a variable number of "regidores" and a "procurador síndico general", known in Salamanca as "sexmero del común". With the ascent to the throne of Carlos III and as a result of his absolutist, centralist and reformist policy two new figures arise into the municipal organizational chart: the "personeros" and the "diputados del común". The objective of this essay is to analyse the origin, operation and ways of election of these six positions and the municipal officials who work next to them.

KEYWORDS: León, Zamora, Salamanca, municipalities, Carlos III, positions and municipal officials.

\section{INTRODUCCIÓN}

El municipio como ente administrativo y de gobierno local, hasta hace poco tiempo, atraía escasamente la atención de los historiadores, los cuales cuando realizaban estudios de tipo local o regional incidían, sobre todo, en los aspectos demográficos, sociales y, principalmente, económicos. No obstante, a partir de la década de los setenta, se observa un mayor interés por el conocimiento de la administración municipal, fundamentalmente por los historiadores del derecho, como González Alonso o Tomás y Valiente. En la actualidad, numerosos historiadores, tanto medievalistas como modernistas centran su línea de investigación en el régimen municipal. Cabría destacar así la existencia de equipos 
especializados en esta cuestión en las universidades de Madrid, Barcelona y Córdoba, entre otras. En esta última funciona, desde 1975, un equipo de investigadores bajo la dirección del profesor Bernardo Ares, que ha introducido elementos nuevos en el estudio institucional, preferentemente dos: una sociología de los individuos que detentan el poder y una interrelación entre los órganos de gobierno y la sociedad gobernada. El resultado es lo que se ha venido a denominar como Historia Social de la Administración.

En este trabajo se pretende realizar un estudio de los municipios de León, Zamora y Salamanca - capitales de sus respectivas provincias y pertenecientes al antiguo Reino de León- a partir del análisis de los cargos existentes en los mismos: corregidores, regidores, procuradores generales... El origen, sus funciones y la forma de elección serán la base desde la cual partir para conocer, de forma breve, un poco más sobre la organización municipal de estas tres ciudades durante el reinado de Carlos III, época en la que se produce la aparición de dos nuevas figuras en los cabildos municipales: los procuradores síndicos personeros y los diputados del común.

En cuanto a las fuentes documentales utilizadas hay que decir que son las Actas Municipales las que mayor información nos han ofrecido para el análisis de cada uno de los cargos, pero también el Catastro del marqués de la Ensenada, del cual hemos extraído los datos cuantitativos necesarios. Dicha documentación ha sido consultada en los archivos de las ciudades de León (A.M.L. Archivo Municipal de León y A.H.P.L. Archivo Histórico Provincial de León), Zamora (A.H.P.Z. Archivo Histórico Provincial de Zamora) y Salamanca (A.M.S. Archivo Municipal de Salamanca).

\section{ORIGEN Y CARACTERÍSTICAS DEL MUNICIPIO BORBÓNICO}

El concejo o cabildo municipal es la institución de gobierno más representativa a nivel local. En su dilatada existencia sufre una serie de alteraciones en su estructura y organización internas debido a varios elementos: autonomía local, intervencionismo estatal, representación popular, predominio oligárquico, etc., dando lugar a la configuración de un modelo de concejo heterogéneo, característica esencial del régimen municipal español ${ }^{1}$.

\footnotetext{
${ }^{1}$ GonzÁlez Beltrán, J. M. (1991). Reformismo y administración local en la provincia de Cádiz durante el reinado de Carlos III. Cádiz: Caja de Ahorros de Jerez, pp. 62-68.
} 
El origen de los concejos locales se remonta a los inicios de la Reconquista, en el siglo X. Este concejo medieval es una institución completamente nueva ${ }^{2}$. En su génesis inciden diversos factores, según los autores. Para González Beltrán ${ }^{3}$ destacan principalmente dos: el económico, que se centra, sobre todo, en la necesidad de administrar los recursos comunes (tierras, pastos, agua, bosques, etc.) y de controlar las actividades y trabajos realizados por el común de los vecinos; y el defensivo, debido al hecho de la reconquista y al paralelo de la repoblación, que convertía a cada vecino en "un soldado que, defendiendo su hogar, guardaba la frontera"4. Además, González Beltrán habla de un tercer factor: el religioso, que "daba unidad y conjunción al grupo de habitantes de un lugar a través de la organización parroquial”. Otro autor, Font Rius, además del factor económico anteriormente citado, señala cinco factores más: políticos, legales, sociales, jurídicos-públicos y subjetivos o de mentalidad $^{5}$. Con esto, por lo tanto, se puede decir que son muchos y muy variados los factores que van a condicionar el nacimiento del municipio.

Son las llamadas asambleas vecinales o "concilium" de las comunidades aldeanas, reunidas en edificios religiosos, las primeras manifestaciones de lo que se viene a denominar como concejo municipal. En estos primeros momentos se caracterizan por una participación ciudadana amplia y sin restricciones, es decir, todos los vecinos intervienen en el gobierno local -es lo que se denomina concejo abierto $^{6}-\mathrm{y}$ por una casi total autonomía frente al poder estatal ${ }^{7}$.

${ }^{2}$ Frente a la tesis romanística, que defiende la pervivencia del municipio romano, prevalece la tesis germanista, introducida en España por HINOJOSA, Eduardo de (1903). Estudios sobre la historia del derecho español. Origen del régimen municipal en León y Castilla. Madrid: Ed. Civitas, que habla de un municipio nuevo con elementos típicamente medievales. Ver también MARTín GaLINDO, J.L. (1987). Poblamiento y actividad agraria tradicional en León. Junta de Castilla y León, p. 27.

3 González Beltrán, J. M. (1991). Reformismo y administración local en la provincia de Cádiz..., p. 62.

${ }^{4}$ Colmeiro, M. (1873). Curso de Derecho Político según la historia de León y Castilla. Madrid, p. 134, cit. en GONZÁLEZ BELTRÁN, J. M. (1991). Reformismo y administración local en la provincia de Cádiz..., p. 62.

${ }^{5}$ Font Rius, J. M. (1946). Origen del régimen municipal en Cataluña. Madrid, pp. 50-65 y 101215.

${ }^{6}$ El concejo abierto de vecinos se define como un órgano de gobierno jurídico y político y es, sin duda, una de las prácticas con más hondas raíces entre las comunidades rurales leonesas, llegando a constituir un elemento clave para el desarrollo de la sociedad leonesa. Ver RUBIO PÉREZ, L.M. (1993). El sistema político concejil en la provincia de León. León: Universidad de León, p. 48.

${ }^{7}$ García de Cortazar apunta que "el concilium o asamblea vecinal es la más antigua fórmula de regimiento de cualquier agrupación humana; su función es entender en los asuntos que afectan al 
Entre los siglos X y principios del XIV la institución municipal mantiene, e incluso aumenta en algunos lugares, su grado de autonomía frente al poder del Estado, debido, principalmente, a la necesidad de los monarcas de tener apoyos con los que contrarrestar a sus posibles opositores. Contrariamente, la representatividad popular va perdiendo fuerza. La evolución del concejo abierto ${ }^{8}$ hacia una fórmula restringida se produce paulatinamente hacia fines del siglo X y principios del XI. Las asambleas de vecinos, ante las demandas de una sociedad en crecimiento, se ven obligadas a encomendar de forma permanente la gestión de múltiples tareas de gobierno a determinados agentes 9 .

En la primera mitad del siglo XIV se produce la primera gran reforma del concejo municipal, alentada e instrumentada por el rey Alfonso XI y sus consejeros, aunque en algunos aspectos, como señala González Alonso, el rey "no hizo sino ratificar jurídicamente una situación preexistente", 10 Estas reformas suponen un duro golpe a la autonomía y democratización de las estructuras municipales medievales. Las modificaciones que se producen son básicamente dos: la introducción en el seno del concejo de las principales ciudades de un representante real, el corregidor ${ }^{11}$, y la institucionalización del regimiento o cabildo

desarrollo de la comunidad" (GARCíA De CORTAZAR, J. A. (1978). La época medieval. Madrid, p. 216). Un buen estudio sobre los concejos en la provincia de León durante la Edad Moderna es el realizado por RUBio PÉREZ, L.M. (1993). El sistema político concejil en la provincia de León. León: Universidad de León.

${ }^{8}$ El concejo abierto sólo terminará perviviendo en las pequeñas comunidades aldeanas, sobre todo del norte de España.

9 Orduña Rebollo, E. (1994). Democracia directa municipal. Concejos y cabildos abiertos. Madrid: Civitas, pp. 58-70.

${ }^{10}$ GonzÁlez Alonso, B. (1981). Sobre el Estado y la Administración de la Corona de Castilla en el Antiguo Régimen. Madrid, p. 63, cit. en GonzÁlez Beltrán, J. M. (1991). Reformismo y administración local en la provincia de Cádiz..., p. 63.

11 Los corregidores son jueces reales que imparten justicia en nombre del rey, ocupan la presidencia del concejo municipal, y controlan la vida municipal en su conjunto. El intervensionismo real en los municipios ya se había producido mucho antes, pues la introducción de jueces reales en los concejos, se tomó como costumbre antes de Alfonso X, siendo práctica habitual en tiempos de Sancho IV, que prodigó el envío de oficiales a las ciudades, y sus sucesores continuaron con la práctica, argumentando los disturbios de la época como razón para su actuación. Recibían en ocasiones la denominación de "juyzes de salario", y otras veces de "juyzes de fuera parte". Ver GonzÁlez Alonso, B. (1970). El Corregidor Castellano (1348-1808). Madrid: Instituto de Estudios Administrativos, p. 25. De la figura del corregidor así como de los regidores se hablará más detenidamente en el siguiente punto. 
cerrado $^{12}$, también conocido como ayuntamiento ${ }^{13}$.

Durante los siglos XVI y XVII los municipios se encuentran sumidos en una aguda crisis causada por tres factores: la pérdida de autonomía y poder municipal motivada por la intervención regia; la patrimonialización o privatización de los oficios concejiles, como nuevo paso en el proceso de degradación de la representatividad popular; $\mathrm{y}$, por último, la conservación de numerosas funciones y competencias a pesar de su decaído papel político $^{14}$.

La llegada al trono español de la dinastía borbónica repercute de forma decisiva en la organización y funcionamiento de los concejos municipales. Ya desde los primeros años del siglo XVIII, se observa un afán del poder central por intervenir en el ámbito local y controlar sus órganos de gobierno, restándoles poder, aunque hay que decir que las principales reformas no se darán hasta los reinados de Carlos III y Carlos IV, principalmente durante el reinado del primero ${ }^{15}$. La intervención del poder estatal persigue la unificación del régimen municipal y la centralización administrativa. Serán los acontecimientos políticos -la guerra de Sucesión al trono español- la causa necesaria para abolir los fueros y regímenes particulares de los reinos de la Corona de Aragón e implantar, a través de los decretos de Nueva

12 El regimiento lo define Emilio Mitre como "un cuerpo colegiado de reducido número de miembros, de extracción hidalga, nobiliaria o altoburguesa, que acabará controlando la vida municipal". Ver Mitre Fernández, E. (1969). La España medieval. Madrid, p. 334. En León, el establecimiento del regimiento se produjo por medio del Diploma Real fechado en Badajoz el 6 de julio de 1345, al que se refiere Díez Canseco y que ha estudiado Ruiz de la Peña con más detalle. Y se complementa la disposición con los documentos expedidos y otorgados por el Rey en Madrid el 6 de noviembre de 1345 y en Alcalá de Henares el 24 de febrero de 1347. Ver DíEz CANSECO, L. (1924). "Sobre los fueros del Valle del Fenar, Castrocalbón y Pajares. Notas para el estudio del Fuero de León", en Anuario de Historia del Derecho, volumen I, Madrid, pp. 327-331; y Ruiz De LA PeÑA, J. I. (1969). "Tránsito del Concejo Abierto al Regimiento en el Municipio Leonés", en León y su historia, volumen I. León: CEISI, pp. 303 y ss.

${ }^{13}$ El ayuntamiento lo constituyen los regidores, y está facultado para administrar todas las rentas del concejo, así como la recaudación de impuestos locales y deudas al concejo, pudiendo prender a los morosos. Las competencias se extienden al nombramiento de los oficios concejiles, anteriormente realizados por la asamblea de vecinos, a la que prohibía reunirse en los sucesivo, bajo duras sanciones. Cit. en Orduña Rebollo, E. (1994). Democracia directa municipal..., p. 79. Hay que añadir que, al hablar de ayuntamiento en esta época y en toda la Edad Moderna no estamos hablando del ayuntamiento que conocemos hoy en día, ya que éste no aparece como tal hasta las reformas liberales del siglo XIX.

${ }^{14}$ Cit. en GONZÁLez BeltrÁN, J. M. (1991). Reformismo y administración local en la provincia de Cádiz..., pp. 64-65.

${ }^{15}$ Ibídem, p. 66. 
Planta, las instituciones castellanas en ellos, logrando así la pretendida unificación ${ }^{16}$.

Los borbones, además de la unificación, quieren someter la organización municipal a una implacable centralización. Esta pretendida centralización, eje de partida de todos los monarcas del dieciocho, la buscan mediante el reforzamiento de la figura del corregidor, que a partir de la Instrucción de 1788 adquiere mayores competencias. También tendrá una gran importancia la creación de los Intendentes ${ }^{17}$, cuya principal finalidad es la de acercar el poder real a los diferentes territorios de la monarquía española, y el surgimiento de los personeros y diputados del común en 1766, como instrumento para restar poder a los regidores. Esta última medida supondrá la vuelta en el concejo municipal de la representatividad ciudadana, además de ser un claro ejemplo de centralismo borbónico.

\section{COMPOSICIÓN DEL MUNICIPIO CAROLINO}

Durante la Edad Moderna en las ciudades de León, Zamora y Salamanca el gobierno de los respectivos municipios lo detenta un corregidor, un alcalde mayor, un número variable de regidores y un procurador síndico general, conocido en Salamanca como sexmero del común. Además, con la subida al trono de Carlos III y como consecuencia de su política absolutista, centralista y reformista surgen dos nuevas figuras dentro del organigrama municipal: los procuradores síndicos personeros y los diputados del común. En este punto se analizará el origen, funcionamiento y forma de elección de estos seis cargos y se hará una breve alusión a los oficiales municipales que trabajan junto a ellos.

\subsection{El corregidor}

La figura del corregidor procede de la Baja Edad Media y desde la época de los Reyes Católicos forma parte de la burocracia estatal, presidiendo el concejo municipal, interviniendo en nombre del rey en la administración local y, con el apoyo de las oligarquías locales, contribuyendo a la desaparición del elemento

${ }^{16}$ Bermejo Cabrero, J. L. (1985). Derecho y Administración Publica en la España del Antiguo Régimen, pp. 81-120.

${ }^{17}$ La figura del intendente es instituida por primera vez en 1711, para ocuparse de la gobernación de los reinos de la Corona de Aragón. En 1718 se generalizará su establecimiento, aunque debido a diversos factores serán abolidos en la mayor parte del territorio. No será hasta 1749 cuando se restablezcan las intendencias en todo el territorio y se aumenten sus competencias, dividiéndose los ramos de justicia, policía, guerra y hacienda con los corregidores. Ver KAMEN, H. (1964). "El establecimiento de los intendentes en la administración española", en Hispania, XXVI, 95. Madrid. 
popular en el municipio. En 1465 parece existir ya un corregidor en todas las ciudades y villas importantes ${ }^{18}$.

El cargo de corregidor responde a un planteamiento netamente centralista, donde su misión fundamental consiste en acercar los municipios al poder real, es decir, aplicar las directrices de la monarquía en el territorio que le está encomendado $^{19}$. El corregidor es el representante y delegado político del rey en el municipio. Sus facultades son muy amplias, desde las judiciales -tanto en lo civil como en lo penal- actuando como juez de primera instancia y, en ciertos casos, como juez de apelación, de residencia y de comisión ${ }^{20}$, hasta las fiscales -ostenta poderes de control en los abastecimientos y precios, interviene en la administración económica municipal y a su vez es delegado de las rentas reales- y militares, pasando por las políticas, gubernativas y administrativas, ya que convoca y preside las reuniones del ayuntamiento y lleva a cabo la ejecución de sus acuerdos ${ }^{21}$.

Tras las Ordenanzas de Felipe V en 1718 por la que se crean nuevos cargos, como el intendente, la figura del corregidor pasa a un segundo plano . De hecho, tras la Ordenanza de Intendentes de 13 de octubre de $1749^{22}$ se establece una Intendencia "a la qual vaya unido el Corregimiento de la Capital"23. Esta situación no durará mucho, ya que Carlos III mediante Real Cédula de 13 de noviembre de 1766 separa definitivamente intendencias de corregimientos, encomendando a los intendentes los ramos de hacienda y guerra, mientras que los corregidores quedan

18 GonZÁlez Alonso, B. (1970). El corregidor castellano (1348-1808)...

${ }^{19}$ El desempeño del cargo de corregidor confiere un gran poder no sólo sobre el municipio que preside, sino también sobre los núcleos poblacionales englobados dentro de los límites del corregimiento. Ver GonZÁLeZ Alonso, B. (1970). El corregidor castellano (1348-1808)..., p. 97.

${ }^{20}$ ANES, G. (1994). “El siglo de las luces”, en ARTOLA, M. (Dir.). Historia de España. Madrid: Alianza Editorial, p. 366.

${ }^{21}$ Guillamón Álvarez, F. J. (1991). “ Del municipio castellano al municipio constitucional”, en Cremades Griñán, C. y Díaz Bautista, A. (coord..). Poder Ilustrado y Revolución. Universidad de Murcia, p. 102.

${ }^{22}$ León, Zamora y Salamanca tienen sus propias intendencias. La de Zamora es una intendencia de ejército y la capital de la misma se situa en la propia capital zamorana; León junto a Asturias, que en este momento aún forma parte de la provincia leonesa, constituyen una intendencia de provincia cuya capitalidad residirá en León; y por último Salamanca, que también tiene una intendencia de provincia, cuya capitalidad oscila entre Ciudad Rodrigo y la propia capital salmantina. GonZÁLEZ Alonso, B. (1970). El corregidor castellano (1348-1808)...,p. 283.

23 “Ordenanza de Intendentes de 13 de Octubre de 1749”, en GonZÁlez Alonso, B. (1970). El corregidor castellano (1348-1808)...,pp. 324-359. 
encargados de la justicia y policía ${ }^{24}$. Sin embargo hubo ciudades donde una misma persona continuó desempeñando simultáneamente los dos cargos, y entre éstas están León, Zamora y Salamanca. El conde de Benagiar en León ${ }^{25}$ y Don Pedro Francisco de Goyeneche en Zamora ${ }^{26}$ se van a perpetuar en el cargo hasta 1769 y 1770 respectivamente con la doble condición de corregidor e intendente. En Salamanca se produce un caso aún más curioso, y es que a pesar de no encontrar al corregidor antes de 1766 ejerciendo las funciones del intendente, sí lo hace a partir de 1787, ya que se produce la restitución de la intendencia de provincia y se adoptan medidas en relación con la distribución de los gastos de traslado de la oficina. En todos los nombramientos de delegados del rey para la ciudad de Salamanca comprendidos entre 1787 y 1801 concurrirá la doble condición de corregidor e intendente de provincia ${ }^{27}$.

Según González Alonso los corregidores pueden ser letrados o bien, militares de capa y espada. Los de capa y espada son personas de estado noble y profesión militar, aunque no tienen mando de tropa. Dentro de esta categoría encontramos también a los gobernadores político y militares, que son corregidores a los cuales les estaba encomendado, además del resto de funciones, el gobierno militar de la ciudad o zona de su jurisdicción. El cargo de corregidor de letras en cambio, está ocupado por letrados ${ }^{28}$. Cuando hablamos de los corregimientos de León ${ }^{29}$, Zamora y Salamanca nos estamos refiriendo a tres corregimientos de capa y espada, aunque a partir de 1787 uno de ellos deja de pertenecer a este grupo para convertirse en corregimiento de letras: Zamora ${ }^{30}$.

${ }^{24}$ Novísima Recopilación, Tomo III, Lib. VII, Tit. XI, Ley XXVI.

${ }^{25}$ A.M.L., Sec. Gobierno, Actas Municipales, Cajas 74 y 75, nº 83, 84 y 85, León, 1766-1769. En la ciudad de León el corregidor es, además, el alcalde mayor del Adelantamiento del Reino de León, instalado en dicha ciudad desde 1638 (VIFORCOS MARINAS, M ${ }^{\mathrm{a}}$ I. (1982). "La instalación del Adelantamiento del Reino en la ciudad de León en 1638", en Tierras de León, n 48, León).

26 A.H.P.Z., Fondo Municipal, Sec. Gobierno, Libros de Actas, L/139, Zamora, 1766; A.H.P.Z., Sec. Abastecimientos, Alhóndiga y Pósitos, Caja n 10, Zamora, 1767-1770.

27 A.M.S., Sec. Gobierno, Libros Consistoriales, Salamanca, 1787-1801.

${ }^{28}$ Ver GonZÁlez Alonso, B. (1970). El corregidor castellano (1348-1808)..., pp. 281-285.

${ }^{29}$ En 1833 aparecerá por primera vez en León la figura del corregidor de letras, desapareciendo la del alcalde mayor, cuyo cargo recaerá en don Ambrosio de Eguía que, será sustituido posteriormente por otros dos letrados. Será paradójicamente un letrado el último corregidor de la ciudad de León. A.M.L., Sec. Gobierno, Actas Municipales, Caja 89, nº 125, León, 1833.

30 GonZÁlez Alonso, B. (1970). El corregidor castellano (1348-1808)..., pp. 281-285. En esta obra podemos encontrar varias tablas donde se da una relación de los corregimientos de capa y espada y de letras en 1711 y 1783 en la Corona de Castilla. 
Los corregidores de capa y espada son asistidos por los alcaldes mayores para lo civil y lo criminal debido a su escasa formación jurídica ${ }^{31}$. Éstos adquieren las funciones del corregidor en caso de que este no compadezca, por enfermedad o por vacante, y actúan como interinos hasta que se produce el nombramiento de un nuevo corregidor por parte del rey. El alcalde mayor aparece sustituyendo al corregidor en numerosas ocasiones, en alguna de ellas incluso durante un año o más. Algunos de estos alcaldes mayores ejercen su cargo en diferentes municipios, como es el caso de don José Fuentes Mangas, que en diferentes momentos lo podemos encontrar en las capitales leonesa (año de 1775) y zamorana (año de $1763)^{32}$.

Durante el reinado de Carlos III late la idea de que los cargos civiles deben ser ejercidos por civiles -letrados preferentemente- y no por militares, ya que provocan el descontento de la población. Se realiza así un movimiento de reconversión de gran parte de los corregimientos de capa y espada en corregimientos de letras ${ }^{33}$, entre ellos, el de Zamora. En 1767 la Cámara propone la transformación de algunos corregimientos de capa y espada -Palencia y Jaen, concretamente- en corregimientos de letras, con el objeto de que los nuevos corregidores pudiesen sustanciar y sentenciar los procesos sin la ayuda del alcalde mayor. Las negociaciones tendrán éxito y cobrarán cada vez mayor amplitud. En 1786 Zamora, aprovechando el fin del gobierno de su corregidor, el brigadier don Vicente Kindelan acude a Floridablanca con peticiones análogas, siendo a partir de ese momento su corregidor un letrado, aunque va a seguir siendo además militar, capitan de guerra más concretamente ${ }^{34}$.

Por último, en cuanto a la duración del cargo, González Alonso habla para el siglo XVI de una duración de dos años, aunque a partir del siglo XVII se va a prorrogar un año más, manteniéndose así durante buena parte del siglo XVIII. A partir de la Real Cédula de abril de 1783, dado que el trienio dejaba un margen de eficacia muy escaso a los corregidores, ya que estimaban que era poco el tiempo para poner en práctica las providencias que considerasen adecuadas para la "buena

${ }^{31}$ Hay que recordar que los corregidores de capa y espada son de profesión militar. Y así parece apreciarse en las actas municipales de León, Zamora y Salamanca, donde se pueden encontrar corregidores de diferente rango militar: capitán, brigadier, alférez...

32 A.H.P.Z., Fondo Municipal, Sec. Gobierno, Libros de Actas, Zamora, 1759 y 1763; A.M.L., Sec. Gobierno, Actas Municipales, León, 1761-1775.

33 GonZÁlez Alonso, B. (1970). El corregidor castellano (1348-1808)..., pp. 256-285.

${ }^{34}$ Ibídem, p. 268; A.H.P.Z., Fondo Municipal, Sec. Gobierno, Libros de Actas, Zamora, 17871808. 
marcha de sus pueblos", se elevó el período a cinco o seis años, ratificándose dicha medida por la Real Cédula de 7 de noviembre de 1799. Además, a los corregidores se les permitirá permanecer en el oficio, aunque haya transcurrido el sexenio, hasta que se incorpore su sucesor, reservándose la monarquía el derecho de introducir modificaciones en casos particulares a los esquemas legales preestablecidos en materia de duración y automatismo ${ }^{35}$. Por eso, tanto en León como en Zamora y Salamanca, hay corregidores que están en posesión de su cargo durante más de seis años. Cabría destacar a don Manuel Joaquín de Vega y Meléndez, que está de corregidor en la ciudad de Salamanca durante siete años seguidos después de haber estado tres unos años antes ${ }^{36}$; don Juan Romualdo Jiménez, que se incorpora al cargo zamorano en el año de 1795 y no lo abandona hasta $1807^{37}$; o a don José Manuel de Miranda y Nabia, que será corregidor de la ciudad de León durante siete años consecutivos (1786-1792) ${ }^{38}$.

\subsection{El alcalde mayor}

El alcalde mayor es la máxima autoridad local en aquellos municipios donde no existe un corregidor, y el auxiliar o asesor jurídico del mismo en el caso de que lo haya y sea de la categoría de capa y espada o gobernador político-militar ${ }^{39}$. La función principal del alcalde mayor consiste en actuar como juez en los pleitos y causas civiles y criminales, además de ocuparse de las cuestiones judiciales y de los asuntos relacionados con el gobierno económico, político y administrativo del municipio $^{40}$. Esta figura, como cita Fernando Albi, aparece ya en la Edad Media, poco después del surgimiento del corregidor ${ }^{41}$, y se perfila desde el principio como figura indispensable para suplir la falta de preparación jurídica del titular del corregimiento $^{42}$.

${ }^{35}$ Ibídem, p. 266.

${ }^{36}$ A.M.S., Sec. Gobierno, Libros Consistoriales, Salamanca, 1759-1761 y 1766-1772.

37 A.H.P.Z., Fondo Municipal, Sec. Gobierno, Libros de Actas, Zamora, 1795-1807.

38 A.M.L., Sec. Gobierno, Actas Municipales, León, 1786-1792.

39 GonZÁlez Alonso, B. (1970). El corregidor castellano (1348-1808)..., p. 267.

40 Bernardo Ares, J.M. de (1978). Los Alcaldes Mayores de Córdoba (1750-1833). Córdoba, pp. 37-41.

${ }^{41}$ Ya lo exige la petición sexta de las Cortes de Toro de 1409 (Novísima Recopilación, Ley XXII, Tit. V, libro III), y en la séptima de las de Toledo de 1525 se concreta un poco más (Novísima Recopilación, Ley X, Tit. V, libro III).

${ }^{42}$ La petición sexta de las Cortes de Toro denomina al corregidor de capa y espada "hombre de Palacio", diciendo de él que "sabe mejor usar de las armas que no leer libros de los fueros y 
La condición militar de los corregidores de las ciudades de León, Zamora y Salamanca y su falta de preparación jurídica para administrar justicia en los pleitos que se efectúan dentro de su jurisdicción, hace necesaria la designación de un letrado -normalmente un abogado de los reales consejos- que les asesore en cuestiones de derecho. Así, el alcalde mayor aparece con frecuencia en los respectivos ayuntamientos junto al corregidor, e incluso sustituyéndole en caso de ausencia, enfermedad o vacante del mismo, ocupando la presidencia del cabildo municipal y desempeñando las demás tareas que aquél tiene encomendadas ${ }^{43}$. Algunos de estos alcaldes mayores, como es el caso de don Manuel Santos Aparicio o don José Fuentes Mangas, ejercen su cargo tanto en León como en Zamora en diferentes momentos. El primero, además, desempeña sus funciones de alcalde mayor en León al mismo tiempo que las realiza en la cabeza de partido de Zamora, poniéndose de manifiesto la cercanía en las relaciones entre ambas ciudades $^{44}$.

Durante la primera mitad del siglo XVIII la designación del alcalde mayor la realiza el corregidor ${ }^{45}$, limitándose la labor del monarca a su aprobación como tal. Sin embargo, a partir de la promulgación de la Ordenanza de intendentes y corregidores de 13 de octubre de 1749, y fruto del auge que experimenta el absolutismo a lo largo de este siglo, la monarquía se apropia dicho derecho, profesionalizándose la carrera del alcalde mayor ${ }^{46}$, y tras la Instrucción de 1788, asimilándose de forma legal sus propias atribuciones y obligaciones ${ }^{47}$.

derechos". Cit. en ALBI, F. (1943). El corregidor en el municipio español bajo la monarquía absoluta. Madrid: Instituto de Estudios de la Administración Local, p. 231.

43 A.M.S., Sec. Gobierno, Libros Consistoriales, Salamanca, 1759-1808; A.H.P.Z., Fondo Municipal, Sec. Gobierno, Libros de Actas, Zamora, 1759-1808; A.M.L., Sec. Gobierno, Actas Municipales, León, 1759-1808.

44 A.H.P.Z., Fondo Municipal, Sec. Gobierno, Libros de Actas, Zamora, 1759-1763 y 1795-1807; A.M.L., Sec. Gobierno, Actas Municipales, León, 1760-1767, 1772-1775 y 1780-1782.

${ }^{45}$ Novísima Recopilación, lib. VII, tit. XI, ley XIX.

${ }^{46}$ GonZÁlez Alonso, B. (1970). El corregidor castellano (1348-1808)..., p. 267. El rey efectúa la elección de entre una terna de sujetos propuestos por la Cámara de Castilla, en la que por regla general se decanta por uno de ellos, aunque en ocasiones prescinde de los letrados que figuran en la terna para inclinarse por otro con cualidades superiores o que cuenta con el apoyo del titular de la Secretaría de Gracia y Justicia, o incluso por la recomendación de alguna figura influyente. Así lo cita Irles Vicente para el caso valenciano en IRLES VICENTE, $\mathrm{M}^{\mathrm{a}}$ del Carmen (1995). El régimen municipal valenciano en el siglo XVIII. Estudio Institucional. Alicante: Institut de Cultura Juan Gil-Albert, pp. 127-128.

${ }^{47}$ GonZÁlez Alonso, B. (1970). El corregidor castellano (1348-1808)..., pp. 364-381. 
La íntima relación existente entre corregimientos y alcaldías mayores se pone de manifiesto nuevamente, a nivel legal, en la duración del ejercicio que tienen asignados ya que, al igual que ocurre con los corregidores, a partir de la Real Cédula de abril de 1783 los alcaldes mayores también pasan de estar tres años en el cargo a seis ${ }^{48}$. Pero se dan casos en los cuales este límite temporal no se cumple: don Manuel Santos Aparicio, don José Fuentes Mangas y don Pedro Pablo de Pereda en León ${ }^{49}$, y don Salvador Hernández, don José Tinto Cebrián y don José de Miret en Salamanca ${ }^{50}$, estarán más de tres años ejerciendo de alcaldes mayores de sus respectivos municipios, probablemente por la concesión de alguna prórroga.

\subsection{Los regidores}

Los regidores constituyen la pieza clave para el gobierno del municipio, de ahí que resulte tan importante para la monarquía controlar la forma de acceso al cargo, así como las cualidades del personal encargado de regentarlo ${ }^{51}$. Toda la estructura orgánica del ayuntamiento está dirigida a garantizar y hacer efectivo el poder de los regidores, ya que son quienes controlan la cúspide de la toma de decisiones, dada su presencia mayoritaria en el pleno ${ }^{52}$.

Si los corregidores y alcaldes mayores tienen, sobre todo, funciones judiciales, las de los regidores son preferentemente de gobierno, es decir, son los encargados de dirigir, vigilar, alentar..., todas las actividades que se ejecutan en el municipio: sanitarias, educativas, policía..., pero sobre todo las económicas y fiscales, como la intervención en todo lo referente a la política de abastos de la ciudad -en principio hasta la aparición de los personeros y diputados del común-, en los fondos públicos y en los pósitos ${ }^{53}$. Además, en cuanto a la puesta en práctica de los acuerdos que se toman en el ayuntamiento, los regidores dominan este ámbito mediante el

48 Ibídem, p. 266

49 A.M.L., Sec. Gobierno, Actas Municipales, León, 1760-1767 y 1772-1779

${ }^{50}$ A.M.S., Sec. Gobierno, Libros Consistoriales, Salamanca, 1764-1767 y 1771-1780.

${ }^{51}$ IRLES ViCENTE, M ${ }^{\text {a }}$ del Carmen (1995). El régimen municipal valenciano..., p.131. Un estudio muy completo de lo que es y representa un regidor en un municipio concreto es el realizado por Guillamón Álvarez, F.J. (1989). Regidores de la ciudad de Murcia. Murcia: Universidad de Murcia.

52 Infante Miguel-Motta, J. (1984). El municipio de Salamanca a finales del Antiguo Régimen. Salamanca: Ayuntamiento de Salamanca, p. 73.

53 GonzÁlez Beltrán, J. M. (1991). Reformismo y administración local en la provincia de Cádiz..., p. 74; A.M.L., Sec. Oficios de Ayuntamiento, Instancias, Comunicaciones y Oficios, Caja 179, nº 48, León, 1803. 
nombramiento de un heterogéneo conjunto de oficiales municipales que se encargan de la labor administrativa del municipio, y de los cuales se hablará más adelante.

En caso de vacante del corregidor, como ya se ha aludido anteriormente, será el alcalde mayor quien ocupe su lugar, asimilando todas sus funciones. ¿Pero qué ocurre cuando el alcalde mayor no puede efectuar dicha sustitución?. Cuando se da este caso, es un regidor el que ocupa la presidencia del ayuntamiento hasta la incorporación del corregidor o del alcalde mayor. A este regidor se le conoce en las fuentes como "regidor decano". Don Tomás Castañón, va a ser el regidor que más veces realizará las tareas del corregidor en la ciudad de León ${ }^{54}$.

Para ser regidor y poder utilizar dicha regiduría los pretendientes tienen que acudir a la Cámara de Castilla con la documentación acreditativa de la pertenencia del oficio, encargándose ésta de la expedición del título, firmado por el rey, una vez incoado y resuelto el correspondiente expediente ${ }^{55}$. A través del cauce del corregidor la Cámara solicita del ayuntamiento una serie de datos relacionados con el pretendiente, efectuándose dicho cometido por medio de los llamados "comisarios de estatuto" que, tras las correspondientes diligencias, presentan un informe del mismo, con cuyo contenido raramente disienten. Estos comisarios son siempre regidores, de manera que el control, implícito en el informe, para el futuro regidor es sumido por quienes en un futuro van a ser sus compañeros ${ }^{56}$. Javier Infante realiza un estudio pormenorizado de dichos informes para la ciudad de Salamanca, para conocer las circunstancias que tienen que concurrir en aquellos que pretenden ocupar la regiduría salmantina, y que podría aplicarse también a las ciudades de León y Zamora. Según este autor parece que, al menos, ya en la primera mitad del siglo XVIII se exige la condición de hidalgo para ser regidor de Salamanca. Situación ésta que, a partir de mediados de siglo, adquiere perfiles

54 Tanto para la ciudad de León como para las de Zamora y Salamanca, los libros de actas nos muestran cada una de las sustituciones que los respectivos regidores decano realizan en el cabildo municipal. En León es donde más veces se aprecia la figura del regidor decano, por lo que se puede afirmar que el corregidor leonés se ausentaba en numerosas ocasiones. En los cabildos zamorano y salmantino el corregidor aparece presidiendo las sesiones plenarias en casi todo momento, por lo que tanto el alcalde mayor como el regidor decano -en menos ocasiones- apenas tenían que cubrir su vacante.

${ }^{55}$ Novísima Recopilación, IV, 5, 11, y VII, 7, 22.

56 Infante Miguel-Motta, J. (1984). El municipio de Salamanca..., p. 46; García MonerRis, E. (1986-1987). "Las vías de acceso al poder local en la Valencia del siglo XVIII. Continuidad y cambio de un proceso de ennoblecimiento de los oficios municipales", en Revista de Historia Moderna. Anales de la Universidad de Alicante, $\mathrm{n}^{\circ}$ 6-7, pp. 47-48. 
inequívocos, ya que mediante una Real Cédula de 7 de julio de 1743, Felipe V concede a la ciudad el "Privilegio de estatuto de nobleza" económica es otro de los requisitos que deben cumplir los pretendientes. Se les exige una renta mínima anual de 5.500 reales que, en 1789 se elevará a 12.000, ya que el ayuntamiento considera que esa cantidad "no sirve para vivir con mucha estrechez" $"$. Además de los puntos anteriormente citados, el pretendiente a regidor no puede tener parientes por consanguinidad o afinidad hasta el cuarto grado -cosa que en algunas ocasiones no se cumple-, desempeñando oficios en el ayuntamiento $^{59}$. Y por último, se exige a los futuros regidores no tener tratos ni actividades comerciales en materias propias de los abastos públicos, ni ejercer por sí mismos oficios manuales que sean objeto de una consideración social negativa. Este último aspecto cambiará con la promulgación de la Real Cédula de 18 de marzo de 1783, que posibilita a los artesanos el acceso a cualquier empleo municipal y al goce de la hidalguía ${ }^{60}$. Tras la realización de un informe por parte de los regidores y expuesto su contenido, éste se remite a la Cámara de Castilla. Una vez cumplimentadas y expuestas todas las diligencias mencionadas, la Cámara procede a la expedición del título, culminando dicho procedimiento con la presentación del mismo en el ayuntamiento y la correspondiente toma de posesión del oficio ${ }^{61}$.

Aunque el procedimiento más habitual para acceder a una regiduría es el que se acaba de mencionar, existen otros métodos como el de la compra o herencia en el caso de las regidurías perpetuas ${ }^{62}$. De este último tenemos un par de ejemplos en

${ }^{57}$ Infante Miguel-Motta, J. (1984). El municipio de Salamanca ..., pp. 46-47.

${ }^{58}$ Ibídem, p. 47.

59 Para el caso de Salamanca, Javier Infante señala que hay quienes obtienen regimientos pese a constar en los informes relaciones de parentesco con otros regidores en ejercicio. Pero esto también se da en León y Zamora, valga mirar simplemente la relación de regidores de ambas ciudades para darnos cuenta de las tupidas relaciones familiares que existen en ambos municipios, al igual que en el salmantino. Ver Libros de Actas de las ciudades de León y Zamora e INFANTE MiguEL-MotTA, J. (1984). El municipio de Salamanca..., p. 48.

${ }^{60}$ Novísima Recopilación, VIII, 23, 8, cit. en Infante Miguel-MotTA, J. (1984). El municipio de Salamanca..., p. 48.

${ }^{61}$ Infante Miguel-MotTA, J. (1984). El municipio de Salamanca..., pp. 48-49.

${ }^{62}$ Los regidores llamados perpetuos o por juro de heredad ejercen una disponibilidad plena e ilimitada, con posibilidad de transmitir su cargo libremente "inter vivos" o "mortis causa", quedando la monarquía obligada a despachar el correspondiente título a favor del nuevo adquiriente o heredero. Sólo se pierden dichas regidurías vitalicias por tres delitos: herejía, lesa majestad y pecado nefando, aunque también existen otros sistemas para abandonar el ayuntamiento antes de que acontezca alguna de las anteriores causas, como son: la renuncia, el traspaso y la venta del cargo. Además de las 
las ciudades de León y Zamora, donde dos regidores que han fallecido: don Juan Francisco Ruizgómez en León y don Ignacio Gómez de la Torre en Zamora dejan sus regidurías en posesión de sus hijos: don Santos Ruizgómez y don Andrés Gómez de la Torre respectivamente ${ }^{63}$.

Tabla 1. $N^{o}$ de regidores por año en las ciudades de León, Zamora y Salamanca (1759-1788)

\begin{tabular}{lccc}
\hline & León & Zamora & Salamanca \\
\hline$N^{o}$ de Regidores & $5-8$ & $14-18$ & $11-22^{*}$ \\
\hline
\end{tabular}

FUENTES: A.M.S., Sec. Gobierno, Libros Consistoriales, Salamanca, 1759-1808; INFANTE MiguELMotTA, J. (1984). El municipio de Salamanca..., pp. 31-32; A.H.P.Z., Fondo Municipal, Sec. Gobierno, Libros de Actas, Zamora, 1759-1808; A.M.L., Sec. Gobierno, Actas Municipales, León, 1759-1808. Elaboración propia.

* A partir de 1804 el número de regidores oscilará entre cuatro y siete.

No sería exagerado afirmar que es muy complicado encontrar al menos dos ciudades que cuenten con un mismo número de regidores ${ }^{64}$. Como se puede apreciar en la Tabla 1, en Salamanca a partir de mediados del siglo XVIII, se contabilizan unos veintidós regidores en ejercicio anualmente. Este número varía a lo largo de los años, como ocurre también en León y Zamora, disminuyendo de forma exagerada a partir de 1804, donde tan sólo se cuentan seis ${ }^{65}$. En Zamora anualmente actúan como regidores entre catorce y dieciocho, conservándose este número hasta finales del Antiguo Régimen ${ }^{66}$. Y por último en León, y a diferencia de las anteriores ciudades, tan sólo nos encontramos, por regla general, entre cinco

regidurías perpetuas también nos podemos encontrar con los oficios renunciables, en los que el titular puede transmitir a otra persona el oficio renunciable siempre y cuando la hacienda acepte dicha transmisión, y en todo caso, cumpliendo determinados requisitos formales legalmente impuestos. El carácter perpetuo o renunciable de los regimientos no tiene ninguna incidencia a la hora del ejercicio de los oficios. En ambos casos los regidores tienen los mismos derechos, gozan de idénticos privilegios y pueden acceder a iguales oficios en el ayuntamiento. IRLES VICENTE, $\mathrm{M}^{\mathrm{a}}$ del Carmen (1995). El régimen municipal valenciano..., pp. 133-134; Para el caso salmantino: INFANTE MIGUELMotTA, J. (1984). El municipio de Salamanca..., pp. 50-56.

63 A.H.P.Z., Fondo Municipal, Sec. Gobierno, Libros de Actas, L/ 152, Zamora, 1779; A.M.L., Sec. Gobierno, Actas Municipales, Caja 77, nº 89, León, 1788.

64 Infante Miguel-Motta, J. (1984). El municipio de Salamanca..., p. 31.

65 A.M.S., Sec. Gobierno, Libros Consistoriales, Salamanca, 1759-1808; También en INFANTE Miguel-MotTA, J. (1984). El municipio de Salamanca ..., p. 31-32.

${ }^{66}$ A.H.P.Z., Fondo Municipal, Sec. Gobierno, Libros de Actas, Zamora, 1759-1808. 
y ocho regidores cada año ${ }^{67}$, en contraste con la cifra que González Dávila da para el siglo XVII, donde habla de veinticinco regidores ${ }^{68}$.

\subsection{Los procuradores síndicos generales y los sexmeros del común}

El procurador síndico general, o sexmero del común -como se le denomina en la ciudad de Salamanca- asiste a las sesiones del Ayuntamiento en representación de los intereses del común, es decir, del vecindario, sin limitación alguna en su intervención. Tiene asignados diversos ramos de policía y gobierno, y defiende los intereses de los regidores ${ }^{69}$.

Es un cargo que en un principio es electivo, pero en el siglo XVIII se halla, en muchas ocasiones, enajenado. Otras veces el procurador síndico es nombrado por el ayuntamiento, e incluso puede recaer dicho cargo en un regidor ${ }^{70}$. En León y Zamora es el propio ayuntamiento el encargado de la elección, a cuya cabeza se sitúan el corregidor y el alcalde mayor. Posteriormente, como sucede con el resto de figuras nombradas anteriormente, el procurador síndico general debe presentar juramento y tomar posesión:

"Haviéndose presentado Don Pedro de Gaztañaga Procurador Sindico General nuevamente electo a efecto de tomar Posesion de su empleo se le salió a recibir según costumbre y haviendo entrado en esta Sala Capitular previas las devidas ceremonias juro en manos de Su Señoria el Señor Alcalde Mayor, según declaro usar y exercer bien y fielmente dicho empleo, y defender el Ministerio de la Purísima Concepción de Maria Santísima que esta ciudad tiene jurado y botado, y en señal de posesion que tomo quieta y pacíficamente se le dio su Asiento.",71

${ }^{67}$ A.M.L., Sec. Gobierno, Actas Municipales, León, 1759-1788.

${ }^{68}$ GonZÁlez Davila, G. (1618). Teatro eclesiástico de la iglesia y ciudad de Salamanca. Vidas de sus obispos, y cosas memorables de su obispado. Salamanca: Imprenta de Antonia Ramírez, p. 345.

${ }^{69}$ Guillamón, J. (1980). Las reformas de la administración local durante el reinado de Carlos III. Madrid: Estudios de la Administración Local, p. 253.

${ }^{70}$ Cit. en DE CASTRO, Concepción (1979). La Revolución Liberal y los municipios españoles. Madrid: Alianza Editorial, p. 41.

${ }^{71}$ A.M.L., Sec. Gobierno, Actas Municipales, Caja 80, nº 99, León, 1807. 
En el municipio de Salamanca, los vecinos, mediante compromisarios, siguen siendo los encargados de elegir anualmente a sus sexmeros del común ${ }^{72}$.

En cuanto al número de procuradores síndicos o sexmeros del común que hay en cada ayuntamiento anualmente hay que decir que, tanto la ciudad de Salamanca como la de Zamora cuentan con dos, a diferencia de la de León, donde tan solo existe un procurador síndico general para todo el común del municipio ${ }^{73}$.

Con la aparición en 1766 de los procuradores síndicos personeros en los ayuntamientos, cuyas funciones, entre otras, tendrán que ver con el común, harán que los procuradores síndicos generales o los sexmeros del común en Zamora y Salamanca terminen desapareciendo de la institución municipal, al menos nominalmente, fusionándose ambos cargos debido a la similitud de sus funciones ${ }^{74}$. Algo parecido cita Francisco Javier Guillamón refiriéndose a la villa de Torremocha, donde el alcalde mayor pide la extinción de uno de los dos cargos debido a la diferencia mínima existente entre ambos:

"Son dos oficiales tan parecidos uno a otro, sin más distinción de que el personero es electo popularmente y el síndico en fuerza de una tradición cuya provisión no consta en los archivos..." 75 .

En León, la figura del procurador síndico general seguirá existiendo como tal junto a la del personero. Lo que diferencia a ambos síndicos desde el plano teórico es que las facultades del primero no tienen limitación alguna en su intervención y, por lo tanto, se extienden más que las del personero, que las tiene más coartadas y limitadas a causa del Auto Acordado y la Instrucción de $1766^{76}$.

\subsection{Los oficiales municipales}

Bajo la denominación de "oficiales y ministros de la ciudad", las Ordenanzas de Salamanca engloban un conjunto heterogéneo de oficiales municipales caracterizado casi en su totalidad por ser elegido periódicamente, normalmente

72 Infante Miguel-Motta, J. (1984). El municipio de Salamanca..., p. 39-40.

73 A.M.S., Sec. Gobierno, Libros Consistoriales, Salamanca, 1759-1766; A.H.P.Z., Fondo Municipal, Sec. Gobierno, Libros de Actas, Zamora, 1759-1766; A.M.L., Sec. Gobierno, Actas Municipales, León, 1759-1766.

74 A.M.S., Sec. Gobierno, Libros Consistoriales, Salamanca, 1759-1766; A.H.P.Z., Fondo Municipal, Sec. Gobierno, Libros de Actas, Zamora, 1759-1766.

75 Guillamón, J. (1980). Las reformas de la administración local..., pp 253-254.

${ }^{76}$ Ibídem, p. 253. 
cada año, por el propio ayuntamiento y por permanecer al margen de la toma de decisiones, ya que estos oficiales no son miembros del cabildo municipal ni, salvo alguna excepción, asisten a sus reuniones. En otro plano, se sitúan una serie de oficios que son provistos, a través de diferentes sistemas, entre los propios regidores $^{77}$, y que son los que mejor se pueden apreciar en los libros de actas de León, Zamora y Salamanca. Cabría resaltar entre los sistemas que se utilizan para la elección de dichos oficios el utilizado en la ciudad de Zamora, donde se realiza por sorteo y con unas bolas de plata:

"Por dichos señores Justicia y Regimiento en conformidad de la costumbre que tienen observada y guardada de muchos años a esta parte que en este dia se hechen las suertes de las comisiones, y empleos de la ciudad para el año que biene, de mil setecientos sesenta y seis, se Acordó asi: Y con efecto haviendo entrado en el cantaro dorado destinado a este fin las volillas de plata con los nombres de los cavalleros capitulares que se hallan presentes, se prozedio a dicho sorteo en esta forma. ",78

La elección de estas "suertes" o "comisiones de turno"79 se realizan de forma anual a finales de cada año o principios del siguiente, según los $\operatorname{casos}^{80}$. Sin embargo es muy frecuente que unas mismas personas desempeñen durante varios años uno o varios oficios, llegando incluso alguno de ellos a estar en dicho cargo durante cuarenta años, como es el caso de don Pedro Cano Mucientes en Salamanca, que ocupa la Contaduría de Propios y Arbitrios entre 1776 y $1805^{81}$. En cuanto a la ocupación de diferentes oficios por una misma persona, aunque se da en las tres ciudades a estudio de la misma manera, cabría resaltar el caso leonés, ya

${ }^{77}$ Infante Miguel-Motta, J. (1984). El municipio de Salamanca..., pp. 32-33.

78 A.H.P.Z., Fondo Municipal, Sec. Gobierno, Libros de Actas, L/139, Zamora, 1766.

${ }^{79}$ En los libros de actas de las ciudades de León, Zamora y Salamanca se puede apreciar cómo a la elección de dichos oficios se le dan múltiples denominaciones: "suertes", "comisiones", "comisiones de turno", "consisitorio general de suertes"...

${ }^{80}$ Mirando en los libros de actas de las ciudades de León, Zamora y Salamanca en el período que se está estudiando se puede comprobar la anualidad de dichas "elecciones" y cómo se realizan a finales de cada año. Para este aspecto también se pueden ver las obras de CASTILlo DE Bovadilla, J. (1978). Política para Corregidores, y Señores de vasallos en tiempo de paz, y de guerra. Y para juezes eclesiásticos y seglares y de Sacas, Aduanas, y de Residencias, y sus Oficiales: y para Regidores, y Abogados, y del valor de los Corregimientos, y Gobiernos Realengos, y de las Ordenes. Madrid: Edición facsímil del Instituto de Estudios de la Administración Local, p. 129; y de Santayana Bustillo, L. (1979). Gobierno politico de los pueblos de España, y el corregidor, alcalde y juez en ellos. Madrid: Instituto de Estudios de la Administración Local, p. 20.

${ }^{81}$ Cit. en Infante Miguel-Motta, J. (1984). El municipio de Salamanca..., p. 34. 
que nos podemos encontrar con algún regidor en quince oficios diferentes, algunos de ellos compartidos, como es el caso de don Jacinto Herrera, que en el año de 1771 aparece como alguacil mayor del campo y de millones, contador de cuentas de propios y arbitrios, contador de millones, guarda mayor de montes... ${ }^{82}$.

Entre los oficiales municipales más importantes cabría destacar algunos, como el "alguacil", el "escribano", los "abogados consistoriales", el "abogado de pobres", el "mayordomo de propios", el "depositario", el "contador", los "alcaldes de la hermandad"..., y de los cuales voy a hacer una breve alusión a continuación.

El "alguacil" es un oficial con funciones ejecutivas que actúa en los tribunales de justicia en nombre del rey ${ }^{83}$.

El "escribano" es el responsable de la formación de las actas, dando fe de los debates y acuerdos que se producen en el ayuntamiento, y poniendo por escrito los juramentos y tomas de posesión de los oficios que se nombren. Además de la redacción de las actas, también le corresponde la confección de diversos libros de contenido municipal y la expedición de documentos (certificados, testimonios...), además de participar en todos los asuntos del municipio que por su carácter público requerían de la presencia de un escribano ${ }^{84}$.

Las ciudades o villas cuentan con uno o más "abogados consistoriales", cuyo cometido consiste en la defensa de los intereses municipales en cuantos asuntos los requiriesen. También nos podemos encontrar con la figura del "abogado de pobres", que es el encargado de defender en los juicios a los presos que carecen de recursos ${ }^{85}$.

El "mayordomo de propios" está directamente vinculado con la administración de las finanzas del municipio. En sus manos se depositan todos los caudales pertenecientes a los propios, arbitrios y regalías, y a su vez se encarga de librar las

82 A.M.L., Sec. Gobierno, Actas Municipales, Caja 74, nº 83, León, 1771.

83 Ver para el caso de Salamanca Infante Miguel-MotTA, J. (1984). El municipio de Salamanca..., pp. 29-30. También contamos con un excelente trabajo de $\mathrm{M}^{\mathrm{a}}$ del Carmen Mairal sobre este oficial y todos los demás cargos que se han citado hasta el momento en el municipio de Málaga durante el reinado de Carlos III (MAIRAL JiMÉnEZ, Ma del Carmen (1990). Cargos y oficios públicos en la Málaga de Carlos III. Málaga: Diputación Provincial de Málaga).

${ }^{84}$ La figura del escribano municipal desde la Edad Media hasta la Época Moderna ha sido estudiada por Corral GarCía, E. (1987). El escribano de Concejo en la Corona de Castilla (siglos XI al XVII). Burgos.

${ }^{85}$ IRLES ViCENTE, Ma del Carmen (1995). El régimen municipal valenciano..., p. 226. 
cantidades que se requieran para satisfacer los distintos capítulos de gastos. En ocasiones esta figura es sustituida por la del "depositario", que tiene las mismas funciones ${ }^{86}$.

Otra figura importante para la buena marcha de la economía del municipio es la del "contador", que tiene como misión específica la contabilidad de los ingresos y gastos del municipio con el fin de evitar fraudes ${ }^{87}$.

Otro de los cargos más representativos dentro del grupo que se está tratando es el de los alcaldes de la hermandad, uno para el estado noble y otro para el estado general. Éstos son los encargados, como alude María del Carmen Irles para el caso valenciano, de "rondar la vega, dando cuenta al corregidor, y denunciándole lo que advierta, sin que pueda formar juicio alguno, ni ajustar o remitir la menor pena sobre delito, ${ }^{, 88}$.

Además de los oficiales mencionados, existen otros muchos como el "maestro de ceremonias", el "guarda mayor de montes", el "defensor del reino", los "comisarios para las fiestas", el "pregonero"..., y otros que adquieren la denominación de "oficios menestrales", y que son muy diferentes a los citados hasta el momento, ya que se trata de oficios cuyo trabajo se realiza manualmente, como son los "alarifes", los "bordadores", los "cuchilleros", los "curtidores", los "herreros", y un largo etcétera que en la ciudad de León, por ejemplo, llega a alcanzar el número de hasta treinta y tres empleos diferentes ${ }^{89}$.

\subsection{Los nuevos cargos municipales: los procuradores síndicos personeros y los diputados del común}

Junto a las reformas hacendísticas, la creación de los procuradores síndicos personeros y los diputados del común es una de las medidas más representativas del reformismo de la segunda mitad del dieciocho. La política absolutista y centralista, en general, y los motines populares de 1766, en particular, están en el origen de la reforma, la cual es considerada por la mayor parte de los investigadores como el principal intento de la legislación borbónica por resolver los graves problemas existentes en el ámbito local.

${ }^{86}$ Un buen estudio sobre el mayordomo de propios es el realizado por CORRAL GARCíA, E. (1991). El mayordomo de Concejo en la Corona de Castilla (s. XIII-s. XVIII). Madrid.

${ }^{87}$ IRLES ViCENTE, $M^{\text {a }}$ del Carmen (1995). El régimen municipal valenciano..., p. 227.

${ }^{88}$ Ibídem, p. 228.

${ }^{89}$ A.M.L., Sec. Gobierno, Actas Municipales, Caja 74, nº 83, León, 1771. 
La diputación del común se puede definir como un cargo público de elección popular indirecta, que se ejerce en un principio de forma anual y a partir de 1770 bianualmente. Los diputados tienen voto, entrada y asiento en el ayuntamiento después de los regidores para intervenir principalmente en todo lo concerniente a los servicios de abastos, asistiendo con voto desde 1767, por una circular del Consejo de 12 de diciembre, a la Junta de Propios y Arbitrios. Actúan también en el control de los mercados públicos, policía urbana y alistamientos de quintas, y participan en la administración de pósitos y en las juntas de policía.

El procurador síndico personero, al igual que los diputados del común, es un cargo público de elección indirecta por parte del pueblo, que se ejerce de forma anual y que en aquellos municipios donde existen dos terminará siendo bianual. El personero también tiene asiento en el ayuntamiento, después del procurador síndico perpetuo, e interviene en todos los actos que celebra el gobierno local. Pero a diferencia de los anteriores tiene voz, aunque no voto, para instar actuaciones que puedan refundar en beneficio del común. Defiende sus intereses proponiendo lo que estima conveniente o formulando reclamaciones en caso de que las decisiones adoptadas por el ayuntamiento, entienda él que perjudican al común de vecinos ${ }^{90}$. Se puede decir que los procuradores síndicos generales son su precedente, y de alguna manera se les viene a sustituir.

El Auto Acordado de 5 de mayo y la Instrucción de 26 de junio de 1766 son las primeras normas que vienen a crear y regular los mencionados oficios. Normas que se ven reforzadas con una continua legislación tendente a delimitar y ampliar competencias, y a mantener los propósitos iniciales ${ }^{91}$. El 15 de mayo de 1766 se convocó a todos los miembros del Ayuntamiento de la ciudad de León para la realización de una sesión extraordinaria en la sala capitular, a cuya cabeza se encontraba el corregidor y alcalde mayor don Juan Francisco Ruiz Gómez, marqués de San Isidro, para dar a conocer a todos el Auto Acordado aprobado por Carlos III y "su Real y Supremo Consejo de Castilla" ${ }^{92}$. El 10 y el 19 de mayo del

${ }^{90}$ Novísima Recopilación, Lib. VII, Tit. XVIII, Ley I, Cap. 5-8, Auto Acordado del Consejo de 5 de mayo de 1766; Novísima Recopilación, Lib. VII, Tit. XVIII, Ley II, Cap. 1-16, Instrucción de 26 de junio de 1766.

${ }^{91}$ Guillamón, J. (1980). Las reformas de la administración local..., p. 31.

92 Gómez MartíneZ, A. (2005). "Las reformas de la administración local en la ciudad de León (1766-1770): personeros y diputados del común", en Actas del Congreso Internacional conmemorativo del II centenario de la muerte del Cardenal Lorenzana. Entre el Barroco y la Ilustración. La época del Cardenal Lorenzana en España y América 1722-1804León: Universidad de León, p. 111. 
mismo año sucederá lo mismo en las ciudades de Salamanca y Zamora ${ }^{93}$.

El Auto Acordado establece la elección de los personeros y diputados del común, pero no estipula nada sobre cómo se deben efectuar dichas elecciones. Para cubrir el vacío legislativo, el 26 de junio el Consejo de Castilla promulga una Real Instrucción con un conjunto de normas que configuran lo que se podría denominar, en palabras del profesor González Beltrán, como "reglamento o ley electoral",94. A pesar de todo, las primeras elecciones se realizan con anterioridad a la mencionada Instrucción: el 28 de mayo en León ${ }^{95}$, el 3 de junio en Salamanca ${ }^{96}$ y el 25 del mismo mes en Zamora ${ }^{97}$. Esta elección, a diferencia de las siguientes, es directa, no hay intervención de comisarios electores, salvo en la ciudad de Zamora donde los vecinos eligen a dos o tres comisarios electores por cada cuadrilla en la que está dividida la ciudad, los cuales se encargan de realizar la votación, como sucederá en los años posteriores ${ }^{98}$.

Dicho Auto Acordado especifica que en aquellas poblaciones de más de dos mil vecinos sean elegidos cuatro diputados y un procurador síndico personero del común, y en las de menos de dos mil, dos diputados y un personero ${ }^{99}$. La ciudad de León contaba, según el Catastro del Marqués de la Ensenada, con 1.390 vecinos con derecho a voto ${ }^{100}$. Por tanto, al no llegar a los dos mil vecinos, sólo saldrán elegidos dos diputados y un síndico personero del común ${ }^{101}$. Zamora, a mediados del siglo XVIII, está alrededor de los dos mil vecinos ${ }^{102}$, por lo que surgen dudas a la hora de elegir el número de diputados y personeros. Una carta del Real Consejo

93 A.M.S., Sec. Gobierno, Libros Consistoriales, 3046/151, Salamanca, 1766; A.H.P.Z., Fondo Municipal, Sec. Gobierno, Libros de Actas, L/139, Zamora,1766.

94 Cit. en GonZÁlez BeltrÁN, J. M. (1991). Reformismo y administración local en la provincia de Cádiz..., p. 101.

95 Gómez MartíneZ, A. (2005). "Las reformas de la administración local en la ciudad de León..., p. 113.

96 A.M.S., Sec. Gobierno, Libros Consistoriales, 3046/151, Salamanca, 1766.

97 A.H.P.Z., Fondo Municipal, Sec. Gobierno, Libros de Actas, L/139, Zamora, 1766.

98 Ibídem.

${ }^{99}$ Novísima Recopilación, Lib. VII, Tit. XVIII, Ley I, Cap. 5-8, Auto Acordado del Consejo de 5 de mayo de 1766.

100 A.H.P.L., Catastro del Marqués de la Ensenada, Caja 8279, leg. 398, León, 1752.

101 Gómez MartíneZ, A. (2005). "Las reformas de la administración local en la ciudad de León..., pp. 112-113.

102 A.H.P.L., Catastro del Marqués de la Ensenada, nº 1776, Zamora, 1752. 
lo aclara: dice que en esta ciudad bastaría con elegir a dos diputados del común, y que los personeros serían los mismos que están ejerciendo el cargo de procurador síndico general, llegándose a "refundir" sus funciones ${ }^{103}$. Para Salamanca, el Catastro de Ensenada nos da una cifra de cuatro mil vecinos escasos, incluyendo eclesiásticos y viudas ${ }^{104}$. Se elegirán, como así especifica la legislación, cuatro diputados del común y dos personeros, que como en el caso zamorano, van a ser los propios procuradores generales.

En las fuentes, en un primer momento, cuando se alude a los personeros o a los procuradores generales, no se aprecia distinción alguna. Tienen que pasar entre uno y dos años para encontrarnos tan sólo con la figura del personero, desapareciendo nominalmente la del procurador síndico general, aunque no funcionalmente, ya que sus funciones se unen a las del personero ${ }^{105}$.

Con la Instrucción de 26 de junio de 1766 se ponen las bases para la elección de los nuevos cargos. Ésta no debe tener lugar en las aldeas, lugares, feligresías y parroquias donde no haya ayuntamiento "porque en tales parajes cesa el fin $y$ objeto del auto acordado". Dicha elección se realiza anualmente de forma indirecta por barrios o parroquias, pudiendo entrar en la votación todos los vecinos seculares y contribuyentes ${ }^{106}$, dejando a un margen a los eclesiásticos. Los vecinos eligen un número determinado de comisarios: veinticuatro si sólo existe una parroquia, y doce por cada parroquia si existen varias, los cuales se encargan de elegir a los personeros y diputados del común. León se encuentra dividida en el dieciocho en trece parroquias. Cada una de ellas elige a doce comisarios electores de la misma clase social, que a su vez eligen al personero y a los dos diputados del común $^{107}$. Las cuatro zonas principales de mayor concentración de población se encuentran en las parroquias de San Martín, Nuestra Señora del Mercado, San

103 A.H.P.Z., Fondo Municipal, Sec. Gobierno, Libros de Actas, L/139, Zamora, 1766.

104 A.H.P.S., Catastro del Marqués de la Ensenada, $\mathrm{n}^{\circ}$ 2038. Salamanca, 1752.

105 A.M.S., Sec. Gobierno, Libros Consistoriales, 3046/151, Salamanca, 1766.

${ }^{106}$ La condición de contribuyente, al igual que la de vecino no estaba nada clara. Durante siglos, ciertos sectores sociales privilegiados habían ido configurando la figura fiscal del exento, es decir, de aquel que no pagaba impuestos, en contraposición al pechero o vecino con obligación de contribuir. Ahora se va a producir un cambio total de dicha actitud, y se va a realzar al contribuyente que, como tal, empieza a tener no ya privilegios sino derechos. Para estas votaciones la acepción contribuyente es tomada en su sentido más amplio, llegándose a considerar que "todo vecino de casa abierta, aunque sea pobre, es contribuyente por lo que consume”. Cit. en GONZÁlEZ BELTRÁN, J. M. (1991). Reformismo y administración local en la provincia de Cádiz..., pp. 103-104.

107 Novísima Recopilación, Lib. VII, Tit. XVIII, Ley II, Cap. 1-16, Instrucción de 26 de junio de 1766. 
Marcelo y San Juan de Regla. Las dos primeras por una razón comercial, porque son el centro, donde están las plazas de la Plegaria, Mayor, Carnicerías y Tiendas. San Marcelo y San Juan de Regla deben su mayor afluencia por razones de tipo burocráticas: la primera porque se encuentra junto a las Audiencias y Ayuntamiento, y la segunda porque está junto a los tribunales eclesiásticos ${ }^{108}$. Zamora se divide en ocho cuadrillas, cada una de las cuales representa la cabecera de varias parroquias. Para cada cuadrilla se eligen también a doce comisarios que se encargan directamente de la elección. Las cuadrillas en las que se divide la ciudad de Zamora son: La Catedral, que comprende las parroquias de San Isidro, San Idefonso y la Magdalena; la de Santa María La Nueva, que comprende las parroquias de San Cipriano y San Bartolomé; la cuadrilla de San Antolín, compuesta por esta parroquia y la de San Esteban; la de San Juan, que es esta parroquia junto con la de San Vicente; la de San Torcuato, compuesta por la Iglesia de Santiago y San Salvador; la cuadrilla de San Leonardo, formada por las parroquias de San Andrés y Santa Eulalia; la de la Horta, comprendida por esta parroquia y la de Santo Tomé; y por último la cuadrilla de Santa Lucía, formada por ésta y por las parroquias de San Simón y San Julián ${ }^{109}$. Salamanca, al igual que ocurre en la ciudad de León, se divide en parroquias, cada una de las cuales elige a los doce compromisarios electores. El número de éstas es de veinticuatro, como se puede apreciar en la Tabla 2, y cabría destacar algunas como La Catedral, San Adrián, San Bartolomé, San Benito, San Boal, San Blas, San Cristóbal... ${ }^{110}$.

Una vez realizada la nominación, los comisarios se reúnen en el ayuntamiento y proceden a ejecutar la elección, en la cual resultan electos todos aquellos que tienen a su favor la respectiva pluralidad de votos. Todos estos actos se realizan delante del escribano y se anotan en un libro particular que trata lo relativo a las elecciones. Los diputados y el personero o personeros que salgan elegidos acuden al día siguiente a tomar posesión y asiento en el ayuntamiento y a prestar juramento ${ }^{111}$. De esta forma se evitaba la ausencia o fallecimiento de los electos antes de desempeñar sus funciones ${ }^{112}$.

${ }^{108}$ A.H.P.L., Catastro del Marqués de la Ensenada, Caja 8279, leg. 398, 1752; MARTín GALINDO,J.L. (1957). La ciudad de León..., p. 66.

109 A.H.P.Z., Fondo Municipal, Sec. Gobierno, Libros de Actas, L/139 y L/151, Zamora,1766 y 1778.

110 A.M.S., Sec. Gobierno, Libros Consistoriales, 3046/151, Salamanca, 1766; A.M.S., Sec. Servicios, Padrón Municipal de Habitantes, 175/1, Salamanca, 1804.

${ }^{111}$ Novísima Recopilación, Lib. VII, Tit. XVIII, Ley II, Cap. 1-16, Instrucción de 26 de junio de 1766.

112 Guillamón, J. (1980). Las reformas de la administración local..., p. 36. 
Cargos y oficios municipales en las ciudades de León, Zamora y Salamanca durante el reinado de Carlos III

Tabla 2. Parroquias o cuadrillas en que se dividen las ciudades de León, Zamora y Salamanca

\begin{tabular}{ccc}
\hline León (parroquias) & Zamora (cuadrillas) & Salamanca (parroquias) \\
\hline San Martín & La Catedral & La Catedral \\
Ntra. Sra. del Mercado & Sta. María La Nueva & San Adrian \\
San Salvador de Palat de Rei & San Antolín & San Bartolomé \\
San Juan de Regla & San Juan & San Benito \\
San Salvador del Nido & San Torcuato & San Boal \\
San Marcelo & San Leonardo & San Blas \\
San Pedro de San Isidro & La Horta & San Cristóbal \\
Santa Marina & Santa Lucía & San Isidoro y San Pelayo \\
San Lorenzo & & San Juan de Barbalos \\
San Pedro de los Huertos & & San Julián \\
San Juan de Renueva & & San Justo \\
Santa Ana & San Marcos \\
Villapérez & San Martín \\
& & San Mateo \\
& & San Pablo \\
& & San Millán \\
& & San Sebastián \\
& Santa Eulalia \\
& & Santa María Magdalena \\
& Sancti - Spiritus \\
& Santiago \\
& Santo Tomás \\
& Santo Tomé \\
& La Trinidad \\
& & leg. 398, 1752; MRTi
\end{tabular}

FuENTES: A.H.P.L., Catastro del Marqués de la Ensenada, Caja 8279, leg. 398, 1752; MARTín Galindo,J.L. (1957). La ciudad de León..., p. 66; A.H.P.Z., Fondo Municipal, Sec. Gobierno, Libros de Actas, L/151, Zamora, 1778; A.M.S., Sec. Servicios, Padrón Municipal de Habitantes, 175/1, Salamanca, 1804. Elaboración propia.

El tratamiento de diputados y personeros es igual al del resto de los cargos municipales: tienen gracias, exenciones y las prerrogativas de las que gozan el resto de los capitulares. Eso sí, no pueden recaer estos oficios en ningún regidor ni individuo del correspondiente ayuntamiento, ni en ninguna persona que esté en cuarto grado de parentesco con los mismos. Además no se necesita distinción de estados, porque pueden recaer tanto en nobles como pecheros. El asiento de los diputados se sitúa a ambas bandas en el ayuntamiento después de los regidores, y 
dejando preferencia al procurador síndico y al personero ${ }^{113}$

Los diferentes historiadores que se han ocupado de la reforma administrativa que a nivel local representa la instauración de los diputados del común y síndicos personeros no se ponen de acuerdo a la hora de valorar positiva o negativamente dicha reforma. Si bien es cierto que la reforma no consiguió restar demasiado poder a los regidores, y que no deja de ser un instrumento más de control dentro del ámbito municipal, la implantación de estos nuevos cargos, al contrario de lo ocurrido con otras iniciativas reformistas -como la aparición de los alcaldes de barrio cuyo resultado no fue el esperado- no fue abandonada y permaneció en vigor hasta el final del Antiguo Régimen. Además, el surgimiento de los personeros y diputados del común supone la incorporación a la vida de los municipios del principio de representación popular, y la oportunidad del pueblo llano de acceder, por primera vez, a los puestos de gobierno municipal.

${ }^{113}$ Novísima Recopilación, Lib. VII, Tit. XVIII, Ley II, Cap. 1-16, Instrucción de 26 de junio de 1766. 